\title{
Influence of Parental Monitoring on Adolescents' Deviant Behaviors as Expressed by Married Adults in llorin Metropolis
}

\author{
Kabir Adewale Adegunju \\ Counsellor Education, University of Ilorin, Ilorin, Nigeria \\ $\bowtie$ adegunjukabir@mail.com
}

\begin{abstract}
Deviant behavior is detrimental to adolescents, and parental monitoring is necessary to forestall this act. Consequently, this study investigated the influence of parental monitoring on adolescents' deviant behavior as expressed by married adults in the llorin metropolis. This study also investigated moderating variables, including gender, age, family type, and religion, on the respondents' view. It employed a descriptive survey method where 200 married adults were selected through simple random and purposive sampling techniques. The participants responded to a questionnaire titled 'Influence of Parental Monitoring on Deviant Behavior Questionnaire' (IPMDBQ).' The instrument's validity was conducted by a team of five experts from Nigeria, and the reliability yielded a correlation coefficient of 0.72 . Besides, t-test and ANOVA statistical tools were employed to test the hypotheses at an alpha level of 0.05 . The result revealed a positive influence of parental monitoring on adolescents' deviant behavior. It was found that there was no significant difference in the respondents' views based on gender, age, family type, and religion. Therefore, it is recommended that parents should monitor their wards appropriately to forestall deviant behavior among adolescents in Nigerian society.
\end{abstract}

Keywords: parental monitoring, deviant behavior, adolescents, married adults

How to Cite: Adegunju, K.A.. (2020). Influence of Parental Monitoring on Adolescents' Deviant Behaviors as Expressed by Married Adults in Ilorin Metropolis. Mimbar Sekolah Dasar, 7(3), 269-283. DOI: http://dx.doi.org/10.17509/mimbar-sd.v7i2.27425

INTRODUCTION There are several stages of human development; childhood, adolescence, and adulthood stages. The adolescent stage spans between 9 years and 21 years. It is characterized by several deviant behaviors (Moffit, 2006), which, if it is not prevented, the behaviors could transcend to the adulthood stage (Merrin et al., 2018). Adolescents have a great deal of energy that could incite them to engage in risk-taking behaviors without considering the consequences. Adolescents are often categorized as youths, which youths are those that any society views as to future leaders. They serve as the primary mechanism for the development of any society. Nonetheless, the act of deviant behavior indiscipline has been a source of concern among stakeholders. Thus, for any significant societal growth, adolescents should be monitored by parents to be of good conduct (Odebode, 2020a).

Peer pressure and family influence are two key factors that influence adolescents' behavior (Fletcher et al., 2004; Trudeau et al., 2012). Several studies found that parental monitoring has a more significant influence than peer influence (Galambos et al., 2003; Trucco et al., 2011). Family is the first environment for children as they learn, grow, and imbibe the actions of the people around them, which are their family members (Dishion \& Patterson, 2006). 
Kabir Adewale Adegunju, Influence of Parental Monitoring on Adolescents' Deviant Behaviors...

One primary process that occurs in the family is parental monitoring. According to Stattin and Ker (2000), parental monitoring is the condition of being aware of the child's whereabouts and actions. Parental monitoring refers to parental tracking and surveillance of the child's behavior (Stattin \& Kerr, 2000). Similarly, Crouter and Head (2002) viewed parental monitoring as parenting actions that include keeping track of the child's movements and actions. In this case, parents must guide and protect their children, particularly adolescents. Parental monitoring has been conceptualized as parents actively tracking their children's behaviors. Parental tracking can be defined as a process or action and dynamic behavior that controls adolescents' rebellious behaviors (Stattin \& Kerr, 2000).

As adolescents grow, they would have less communication with their parents because they are adults. They believe that they could make decisions on their own (Haynie \& Osgood, 2005). However, parents who perform their responsibilities would create communication channels with the children and develop their relationship with their children. Parents would be aware of their children's daily activities, friends, interests, and experiences (Snyder, 2002). It is important to note that adolescents usually spend less time with their parents in the development process from childhood to adolescence. And may even have discord and misunderstanding with their parents, where they prefer to confide more with peers and engage in unsupervised behaviors. These behaviors are usually considered deviant (Laird et al., 2008).

Deviant behaviors are actions that violate acceptable behaviors in society (Colman, 2014). Moreover, according to Hundert (2011), deviant behavior is a departure from the norms and values that, in turn, engages the deviant's life and the people around him. In the last few decades, Nigeria has witnessed a tremendous increase in deviant behaviors, especially among youths and adults (Yahaya, 2015). These acts have given the nation a negative image globally. These behaviors include fraud, arson, cultism, violent reactions, kidnapping, examination malpractices (Yahaya et al., 2017; Odebode et al., 2017), drug abuse, sex abuse, armed robbery, and corruption (Odebode, 2020a). The alarming rate of deviant behaviors led to the establishment of the National Drug Law Enforcement Agency (NDLEA), the Independent Corrupt Practices and other related offenses Commission (ICPC), and National Agency for Food and Drug Administration and Control (NAFDAC). Despite the establishment of these agencies, deviant behaviors have increased (Yahaya, 2015). In this case, Miranda and Claes (2004) identified five types of deviant behaviors, which are violence, theft, street gangs, mild drug use, and drug use. These deviant behaviors occur because children are exposed to visual media at an early age when they do not have proper orientation from parents and other socialization agents to access visual media (Odebode, 2019). On the premise of this background information, this study focuses on the 
influence of parental monitoring on adolescents' deviant behavior as expressed by married adults in the llorin metropolis.

\section{Problem}

The rate of deviant behavior is getting increasingly high by the day in Nigeria. Adolescents have turned into criminals and performing actions that violate the social norms such as rape, kidnapping, armed robbery, stealing, addiction to drugs, thuggery, internet fraud, and examination malpractices (Yahaya, 2015). Even worse, the aftermaths of deviant behavior are not farfetched; parents are heartbroken, resources in the society are damaged and wasted, personal resources are wasted, feelings of regret, poor self-image (Odebode, 2020b), and loss of lives. A question is raised whether parents' role in monitoring their wards or whether parental monitoring does not influence adolescents.

Several studies have been conducted on parental monitoring. For instance, Barnes et al. (2000) examined the effects of parenting on adolescent alcohol misuse development: a sixwave latent growth model. On the other hand, DeVore and Ginsburg (2005) analyzed the protective effects of good parenting on adolescents. Also, Barnes, Hoffman, Welte, Farrell, and Dintcheff (2006) examined the effects of parental monitoring and peer deviance on substance use and delinquency. Similarly, Fosco et al. (2012) studied family relationships and parental monitoring during middle school as predictors for early adolescent problem behavior. Oluyemi et al. (2017) also studied the parental influence on adolescent sexual behavior among secondary school students in Ogbomoso, Nigeria. Furthermore, Odukoya et al. (2018) explored parental monitoring and substance use among youths, a survey of high school adolescents in Lagos State, Nigeria.

Many of these studies were conducted in different parts of the country. And the world and, likewise, different dimensions of adolescents were also examined, and different participants were considered. Therefore, this study examined the influence of parental monitoring on adolescents' deviant behavior as expressed by married adults in llorin metropolis, Kwara State, Nigeria, to bridge the previous studies gap.

\section{Research Question}

1. What influence does parental monitoring have on adolescents' deviant behavior as expressed by married adults in the llorin metropolis? 
Kabir Adewale Adegunju, Influence of Parental Monitoring on Adolescents' Deviant Behaviors...

\section{Hypotheses}

1. There is no significant difference in the influence of parental monitoring on adolescents' deviant behavior as expressed by married adults in llorin metropolis, Kwara State, based on gender.

2. There is no significant difference in the influence of parental monitoring on adolescents' deviant behavior as expressed by married adults in llorin metropolis, Kwara State, based on age.

3. There is no significant difference in parental monitoring on adolescents' deviant behavior as expressed by married adults in Ilorin metropolis, Kwara State, based on the family type.

4. There is no significant difference in the influence of parental monitoring on adolescents' deviant behavior as expressed by married adults in llorin metropolis, Kwara State, based on religion.

\section{METHOD}

\section{Design}

This study investigated the influence of parental monitoring on adolescents' deviant behavior as expressed by married adults in llorin metropolis, Kwara State. For this purpose, a descriptive study survey was employed. A survey is appropriate for this study, which aimed at factually describing a particular phenomenon. This study used the questionnaire method as the instrument to describe the strategies for curbing indiscipline.

\section{Procedures for Sampling the Participants}

Nigerian teachers formed the population for this study included elementary school teachers in Nigeria. However, the target population in which the sample was drawn consisted of married adults in Ilorin metropolis, Kwara State, Nigeria. The purposive sampling procedure was employed to choose five densely populated communities in llorin to select the sample. The systematic random sampling technique was adopted to select 40 participants from the earlier selected communities. This procedure amounted to a total of 200 married adults that were chosen for the study.

\section{Instrumentation}

For this study, a questionnaire titled 'Influence of Parental Monitoring on Deviant Behavior Questionnaire' (IPMDBQ)' was developed and implemented to gather the required information. The instrument consisted of sections A and B. Section A consisted of the 
demographic data of the participants. Section B consisted of twenty items on the influence of parental monitoring on deviant behavior.

Validity: that an instrument adequately measures what it was designed to assess means the instrument has validity. IPMDBQ merited this quality by giving copies to five academics that have the expertise for checking the validity of any instrument. These experts vetted and modified some items to suit their purpose. The corrections made on the instrument were affected, and the final draft of IPMDBQ was adjudged valid for this study.

Reliability: to adjudge that an instrument is reliable, the instrument must have measured consistently over a certain administration period. The reliability of IPMDBQ was ascertained through the re-test reliability procedure. The studies administered IPMDBQ twice on 20 married adults in the llorin metropolis at an interval of three weeks. These sets of scores generated were subjected to analysis using Pearson's Product Moment Correlation statistics and produced a correlation coefficient of 0.72. Therefore, it can be concluded that IPMDBQ was reliable as an instrument for this study.

\section{Scoring Procedure of the Instrument}

Section A, which elicited demographic information, was scored using percentage. Section B, which elicited information on the influence of parental monitoring on deviant behavior, was scored through the assignment of scores to each response. It is indicated that for any Strongly Agree response, 4 points are assigned; Agree, 3 points are assigned; Disagree, 2 points are assigned and Strongly Disagree, 1 point is assigned. Thus, the mean score that any item will have is 2.50. It is further indicated the item could be scored between 1 and 4 with 2.5 as the benchmark for making a decision. Any Item with 2.5 and above was regarded as a positive influence of parental monitoring on deviant behavior. In contrast, items scored below 2.5 were regarded as the negative influence of parental monitoring on deviant behavior.

\section{Procedures for Administering the Instrument and Collection of Data}

IPMDBQ was distributed to the respondents who were willing to participate in the study. It was conducted with the support of several assistants who were well informed on the administration's necessity. The participants were also briefed appropriately on the administration and were given enough time to respond to IPMDBQ. Then, the questionnaires were collected on the spot to ensure a $100 \%$ retrieval rate. 
Kabir Adewale Adegunju, Influence of Parental Monitoring on Adolescents' Deviant Behaviors...

\section{Method of Data Analysis}

Section A of IPMDBQ was analyzed using percentage, while section B was analyzed using †test and Analysis of Variance and decision made at 0.05 alpha level.

\section{RESULTS}

This study investigated the influence of parental monitoring on adolescents' deviant behavior as expressed by married adults in the llorin metropolis. In this study, a total of 200 questionnaires were administered, and all of them were collected. It was possible because the questionnaires were collected on the spot, resulting in a $100 \%$ return rate of the instrument. In this section, the analysis of the demographic data and the hypotheses for the study is covered.

\section{Demographic Data}

The demographic data were analyzed using descriptive statistics of percentage. It is presented as follows:

Table 1. Distribution of Respondents by Gender, Age, Family Type, and Religion

\begin{tabular}{llcl}
\hline Variables & & Frequency & Percentage\% \\
\hline Gender: & & \\
& Male & 93 & 46.5 \\
& Female & 107 & 53.5 \\
& Total & 200 & 100
\end{tabular}

Age:

$\begin{array}{lcc}20-30 \text { years } & 60 & 30.0 \\ 31-40 \text { years } & 33 & 16.0 \\ 41 \text { ears \& Above } & 108 & 54.0 \\ \text { Total } & \mathbf{2 0 0} & \mathbf{1 0 0}\end{array}$

Family Type:

$\begin{array}{lrl}\text { Monogamous } & 106 & 53.0 \\ \text { Polygamous } & 94 & 47.0 \\ \text { Total } & 200 & 100\end{array}$

Religion:

$\begin{array}{lrl}\text { ATR } & 3 & 1.5 \\ \text { Christianity } & 105 & 52.5 \\ \text { Islam } & 92 & 57.5 \\ \text { Total } & \mathbf{2 0 0} & 100\end{array}$

Table 1 presents the demographic characteristics of the respondents. It shows that among the 200 respondents who participated in the study, 93 (46.5\%) of them are males, while 107 (53.5\%) of them are females. Similarly, 60 (30.0\%) of the respondents are between 20-30 years old, $32(16.0 \%)$ of the respondents are between $31-40$ years old, and 108 (54.0\%) of the 
respondents are between 41 years old and above. The table shows that 106 (53.0\%) of the respondents are from the monogamous family, while 94 (47.0\%) of the respondents are from polygamous families. It also shows that $3(1.5 \%)$ of the respondents practice African Traditional Religion, 105 (52.5\%) of the respondents practice Christian while, 157 (78.5\%) of the respondents practice Islam.

Research Question 1:

What influence does parental monitoring have on adolescents' deviant behavior as expressed by married adults in llorin metropolis, Kwara State

Table 2. Mean and Rank Order of Respondents' Expression on the Influence of Parental Monitoring on Deviant Behaviors Among Adolescents

\begin{tabular}{|c|c|c|c|}
\hline \multicolumn{2}{|c|}{ Item No. Parental Monitoring: } & \multirow{2}{*}{$\begin{array}{c}\text { Mean } \\
3.57\end{array}$} & \multirow{2}{*}{$\begin{array}{l}\text { Rank } \\
\text { Order } \\
1^{\text {st }}\end{array}$} \\
\hline 5. & Decreases chances of joining bad gangs & & \\
\hline 6. & Reduces risk-taking behaviors among peers & 3.54 & $2^{\text {nd }}$ \\
\hline 4. & Increases alcohol refusal efficacy & 3.53 & 3rd \\
\hline 18. & Discourages adolescents from drug abuse & 3.50 & $4^{\text {th }}$ \\
\hline 19. & Discourages adolescents from disobeying constituted authorities & 3.46 & $5^{\text {th }}$ \\
\hline 20. & Discourages adolescents from involvement in sexual activities & 3.42 & $6^{\text {th }}$ \\
\hline 14 & Helps parents rightly guide their children & 3.41 & $7^{\text {th }}$ \\
\hline 3. & Curbs sexual debut among adolescents & 3.40 & $8^{\text {th }}$ \\
\hline 7. & Has a protective effect on adolescents' academic outcome & 3.29 & $9^{\text {th }}$ \\
\hline 1. & Prevents adolescents from drug initiation & 3.28 & $10^{\text {th }}$ \\
\hline 2. & Help prevent alcohol initiation among adolescents & 3.24 & $11^{\text {th }}$ \\
\hline 8. & Has a positive effect on adolescents' social adjustment & 3.22 & $12^{\text {th }}$ \\
\hline 11. & Increases likelihood of completing assignments independently & 3.20 & $13^{\text {th }}$ \\
\hline 13. & Improves adolescents self-disclosure to their parents & 2.92 & $14^{\text {th }}$ \\
\hline 16. & $\begin{array}{l}\text { Effective in reducing opportunities for young people's } \\
\text { association }\end{array}$ & 2.90 & $15^{\text {th }}$ \\
\hline 9 & Helps adolescents personality development & 2.84 & $16^{\text {th }}$ \\
\hline 12 & $\begin{array}{l}\text { Decreases lots of adolescents from skipping school or being } \\
\text { suspended }\end{array}$ & 2.80 & $17^{\text {th }}$ \\
\hline 17 & Helps motivate adolescents to be honest in all their dealings & 2.66 & $18^{\text {th }}$ \\
\hline 10 & Improves parents-adolescents relationship & 2.62 & $19^{\text {th }}$ \\
\hline 15 & Checks adolescents' misuse of social media & 2.60 & $20^{\text {th }}$ \\
\hline
\end{tabular}

Table 2 shows the mean and rank of the influence of parental monitoring on deviant behavior of adolescents as expressed by married adults in Ilorin metropolis, Kwara State. Since the cutoff point for deciding on the influence of parental monitoring on adolescents' deviant behavior as expressed by married adults in Ilorin metropolis, Kwara State is 2.5, and all the items have mean scores above the cut-off point. Therefore, it can be concluded that the influence of parental monitoring on adolescents' deviant behavior as expressed by married adults in Ilorin metropolis, Kwara State, is positive. It was found that parental monitoring decreases adolescents' chances of joining bad gangs, reduces risk-taking behaviors, increases alcohol refusal efficacy, discourages adolescents from drug abuse, disobeys 
Kabir Adewale Adegunju, Influence of Parental Monitoring on Adolescents' Deviant Behaviors...

constituted authorities, and involves risky sexual activities.

\section{Hypotheses Testing}

Four null hypotheses were formulated and tested for this study. The hypotheses were tested using t-test and ANOVA statistical methods at 0.05 level of significance. The results are presented as follows:

\section{Hypothesis One:}

There is no significant difference in the influence of parental monitoring on deviant behavior of adolescents as expressed by married adults in llorin metropolis, Kwara State, based on gender

Table 3. Mean, Standard Deviation and t-value Showing the Influence of Parental Monitoring on Deviant behavior of Adolescents as Expressed by Married adults in llorin metropolis, Kwara State Based on Gender

\begin{tabular}{lcccccc}
\hline Gender & N & Mean & SD & df & $\begin{array}{c}\text { Cal. } \\
\text { t-value }\end{array}$ & $\begin{array}{c}\text { Crit. } \\
\text { t-value }\end{array}$ \\
\hline Male & 93 & 64.02 & 14.11 & & & \\
Female & 107 & 69.14 & 12.00 & 198 & 0.86 & 1.96 \\
\hline
\end{tabular}

Table 3 shows that the calculated t-value of 0.86 is less than the critical t-value of 1.96 . Since the calculated t-value is less than the critical t-value. It can be concluded that there is no significant difference in the influence of parental monitoring on deviant behavior of adolescents as expressed by married adults in the Ilorin metropolis, Kwara State, based on gender. Thus, the hypothesis is accepted.

\section{Hypothesis Two:}

There is no significant difference in the influence of parental monitoring on deviant behavior of adolescents as expressed by married adults in llorin metropolis, Kwara State, based on age

Table 4. Analysis of Variance (ANOVA) on the Influence of Parental Monitoring on Deviant behavior of Adolescents as Expressed by Married adults in Ilorin metropolis, Kwara State Based on Age

\begin{tabular}{llcccll}
\hline Age Diff. & SS & df & MS & $\begin{array}{l}\text { Cal.F- } \\
\text { ratio }\end{array}$ & $\begin{array}{l}\text { Crit. Decision } \\
\text { F-ratio }\end{array}$ \\
\hline Between-group & 437.86 & 2 & 218.93 & 1.59 & 3.00 & N Sig. \\
Within-group & 270002.231 & 197 & 137.06 & & & \\
Total & 31645.87 & 199 & & & & \\
\hline
\end{tabular}


Table 4 indicates that the calculated F-ratio is 1.59 , while the critical F-ratio is 3.00 . Since the calculated F-ratio of 1.59 is less than the critical F-ratio of 3.00 at 0.05 level of significance, the hypothesis can be accepted. It means that there is no significant difference in the influence of parental monitoring on adolescents' deviant behavior as expressed by married adults in llorin metropolis, Kwara State, based on age.

\section{Hypothesis Three:}

$$
\begin{aligned}
& \text { There is no significant difference in the influence of } \\
& \text { parental monitoring on deviant behavior of } \\
& \text { adolescents as expressed by married adults in Ilorin } \\
& \text { metropolis, Kwara State, based on family type }
\end{aligned}
$$

Table 5. Mean, Standard Deviation and t-value showing the Influence of Parental Monitoring on Deviant behavior of Adolescents as Expressed by Married adults in llorin metropolis, Kwara State Based on Family Type

\begin{tabular}{lcccccc}
\hline Family Type & $\mathbf{N}$ & Mean & SD & df & $\begin{array}{c}\text { Cal. } \\
\text { t-value }\end{array}$ & $\begin{array}{c}\text { Crit. } \\
\text { t-value }\end{array}$ \\
\hline Monogamy & 106 & 68.32 & 10.24 & & & \\
Polygamy & 94 & 70.01 & 8.20 & 198 & 1.24 & 1.96 \\
\hline
\end{tabular}

Table 5 shows that the calculated t-value of 1.24 is less than the critical t-value of 1.96. Since the calculated t-value is less than the critical t-value, it can be concluded that there is no significant difference in the influence of parental monitoring on the deviant behavior of adolescents. As expressed by married adults in the llorin metropolis, Kwara State, the hypothesis can be accepted based on the family type.

\section{Hypothesis Four:}

There is no significant difference in the influence of
parental monitoring on deviant behavior of
adolescents as expressed by married adults in Ilorin
metropolis, Kwara State, based on religion

Table 6. Analysis of Variance (ANOVA) on the Influence of Parental Monitoring on Deviant behavior of Adolescents as Expressed by Married adults in Ilorin metropolis, Kwara State Based on Religion

\begin{tabular}{lccclll}
\hline Rel. Diff. & SS & df & MS & $\begin{array}{l}\text { Cal. F- } \\
\text { ratio }\end{array}$ & $\begin{array}{l}\text { Crit. Decision } \\
\text { F-ratio }\end{array}$ \\
\hline Between-group & 517.078 & 2 & 258.53 & 1.87 & 3.00 & N Sig. \\
Within-group & 27182.371 & 197 & 137.98 & & & \\
Total & 31645.87 & 199 & & & & \\
\hline
\end{tabular}


Kabir Adewale Adegunju, Influence of Parental Monitoring on Adolescents' Deviant Behaviors...

Table 6 indicates that the calculated F-ratio is 1.87, while the critical F-ratio is 3.00 . Since the calculated F-ratio of 1.87 is less than the critical F-ratio of 3.00 at a 0.05 level of significance, the hypothesis can be accepted. It can be concluded that there is no significant difference in the influence of parental monitoring on deviant behavior of adolescents as expressed by married adults in Ilorin metropolis, Kwara State, based on religion.

\section{DISCUSSION}

The finding revealed that the influence of parental monitoring on adolescents' deviant behavior as expressed by married adults in Ilorin metropolis, Kwara State, is positive. It was found that parental monitoring decreases adolescents' chances of joining bad gangs, reduces risk-taking behaviors, increases alcohol refusal efficacy, discourages adolescents from drug abuse, disobeys constituted authorities, and involves risky sexual activities. This finding is in line with Oluyemi et al. (2017), who found a significant relationship between participants' sexual behavior and parental communication and parental monitoring. Similarly, the finding tallies with Odukoya et al. (2018), who analyzed parental monitoring and substance use among youths: a high school adolescent survey in Lagos State, Nigeria. The finding implies that parents have a strong influence on their wards. They are solely responsible for their children's overall development, including curbing or bringing to the barest minimum, deviant behavior.

The hypothesis stated that there was no significant difference in the influence of parental monitoring on adolescents' deviant behavior as expressed by married adults in llorin metropolis, Kwara State, based on gender, was accepted. It can be concluded that there was no significant difference in the influence of parental monitoring on deviant behavior of adolescents as expressed by married adults in Ilorin metropolis, Kwara State, based on gender. It can be further concluded that whether the respondents are males or females, they did not express the influence of parental monitoring on adolescents' deviant behavior differently. This finding is in line with that of Fletcher et al. (2004) and Trudeau et al. (2012), who found no significant difference in the influence of parental monitoring on adolescents' deviant behavior based on gender.

The hypothesis stated that there was no significant difference in the influence of parental monitoring on adolescents' deviant behavior as expressed by married adults in llorin metropolis, Kwara State, based on age, was accepted. It shows no significant difference in the influence of parental monitoring on adolescents' deviant behavior as expressed by married adults in Ilorin metropolis, Kwara State, based on age. It can be further concluded that whether the respondents are young or old, it did not affect their expressions on the influence of parental monitoring on adolescents' deviant behavior differently. This finding corresponds with Galambos et al. (2003) and Trucco et al. (2011), who found no significant 
difference in the influence of parental monitoring on adolescents' deviant behavior based on age.

The hypothesis stated that there was no significant difference in parental monitoring of adolescents' deviant behavior as expressed by married adults in the llorin metropolis. Kwara State, based on the family type, was accepted. It can be concluded that there was no significant difference in the influence of parental monitoring on deviant behavior of adolescents as expressed by married adults in Ilorin metropolis, Kwara State, based on the family type. It can be further interpreted whether the respondents are from monogamous and polygamous families. They did not express the influence of parental monitoring on the deviant behavior of adolescents differently. This finding agrees with Haynie and Osgood (2005) and Snyder (2002), who revealed that family type has no significant difference in the influence of parental monitoring on adolescents' deviance. It could be because there are no religions that preach the lack of tracking by parents as religions expect parents to encourage, guide, and monitor their children. Based on this, the expressions of the respondents will not differ.

The hypothesis stated that there was no significant difference in the influence of parental monitoring on adolescents' deviant behavior as expressed by married adults in llorin metropolis, Kwara State based on religion was accepted. It means that there was no significant difference in the influence of parental monitoring on adolescents' deviant behavior as expressed by married adults in Ilorin metropolis, Kwara State, based on religion. It can be further concluded that whether the respondents are Christians, Muslims, or African Traditional worshippers, they did not express the influence of parental monitoring on adolescents' deviant behavior differently. This finding is in line with Stattin and Kerr (2003) and Crouter and Head (2002), who revealed that religion had no significant difference in the influence of parental monitoring on adolescents' deviance.

\section{CONCLUSION}

It was found that the influence of parental monitoring on adolescents' deviance is positive. It was revealed that parental monitoring decreased adolescents' chances of joining bad gangs, reducing risk-taking behaviors, increasing alcohol refusal efficacy, discouraging adolescents from drug abuse, disobeying constituted authorities, and risky sexual activities. Similarly, there was no significant difference in the influence of parental monitoring on adolescents' deviant behavior as expressed by married adults in the llorin metropolis based on gender, age, family type, and religion.

\section{RECOMMENDATIONS}

Based on the conclusion of this study, the following recommendations were made: 
Kabir Adewale Adegunju, Influence of Parental Monitoring on Adolescents' Deviant Behaviors...

1. Parents are the key aspects of ensuring that adolescents are well-groomed. Therefore, counselors should enlighten parents on the influence of their monitoring activities in curbing adolescents' deviant behaviors.

2. Counselors should assist counsel and establish a parents-children relationship to realize an all-round monitoring and learning activity. It could help adolescents in reducing deviant behaviors and reducing vices in society.

3. Counselors should develop programs to support parents in monitoring adolescents and ensure that deviant behaviors are curbed in society. Counselors need to orientate parents on the implications of deviant behaviors among adolescents and the influence of parental monitoring on such behaviors.

4. Parents should seek a professional counselor's assistance on effectively monitoring their children for the benefit of themselves and the people around them. They should be there for parents, adolescents, and other stakeholders to work together to curb deviant behaviors among adolescents when necessary. Counselors must operate an open door policy and be ready to attend to parents who have concerns on their wards. Such parents should be accepted and assisted.

5. In addition to the prize giving in schools, the Government should encourage parents whose children are well behaved. It will serve as encouragement for other parents to monitor their children strictly.

6. Programs focusing on adolescents' deviant behaviors should also be organized so that they can be aware of the implications of deviant behaviors.

\section{REFERENCES}

Barnes, G.M., Hoffman, J.H., Welte, J.W., Farrell, M.P., \& Dintcheff, B.A. (2006). Effects of parental monitoring and peer deviance on substance use and delinquency. Journal of Marriage and Family, 68(4), 1084-1 104. https://doi.org/10.1111/j.1741-3737.2006.00315.x.

Barnes, G.M., Reifma, A.S., Farrell, M.P., \& Dintcheff, B.A. (2000). The effects of parenting on the development of adolescent alcohol misuse: A six-wave latent growth model. Journal of Marriage and the Family, 62(1), 175-186. https://doi.org/10.1111/j.1741-3737.2000.00175.x.

Crouter, A.C. \& Head, M.R. (2002). Parental monitoring and knowledge of children. Handbook of Parenting, 3, 461-483. 
DeVore, E.R., \& Ginsburg, K.R. (2005). The protective effects of good parenting on adolescents. Current Opinion in Pediatrics, 17(4), 460-465. https://doi.org/10.1097/01.mop.0000170514.27649.c9.

Dishion, T.J., \& Patterson, G.R. (2006). The development and ecology of antisocial behavior in children and adolescents In Cicchetti D, \& Cohen DJ (Eds.), Developmental Psychopathology, Vol 3: Risk, disorder, and adaptation (pp. 503-541). Hoboken, NJ: Wiley.

Fosco, G.M., Stormshak, E.A., Dishion, T.J., \& Winter, C.E. (2012). Family relationships and parental monitoring during middle school as predictors for early adolescent problem behavior. Journal of Clinical Child \& Adolescent Psychology, 41(2), 202-213. https://doi.org/10.1080/15374416.2012.651989.

Fletcher, A.C., Steinberg, L., \& Williams-Wheeler, M. (2004). Parental influences on adolescent problem behavior: Revisiting Stattin and Kerr. Child Development, 75(3), 781-796. https://doi.org/10.1111/j.1467-8624.2004.00706.x.

Galambos, N.L., Barker, E.T., \& Almeida, D.M. (2003). Parents do matter: Trajectories of change in externalizing and internalizing problems in early adolescence. Child Development, 74(2), 578-594. doi:10.1111/1467-8624.7402017.

Haynie, D.L., \& Osgood, D.W. (2005). Reconsidering peers and delinquency: How do peers matter? Social Forces, 84(2), 1109-1130. https://doi.org/10.1353/sof.2006.0018

Laird, R.D., Criss, M.M., Pettit, G.S., Dodge, K.A., \& Bates, J.E. (2008). Parents' monitoring knowledge attenuates the link between antisocial friends and adolescent delinquent behavior. Journal of Abnormal Child Psychology, 36(3), 299-310. https://doi.org/10.1007/s10802-007-9178-4.

Merrin, G., Davis, J.P., Berry, D., \& Espelage, D.L. (2018). Developmental Changes in Deviant and Violent Behaviors from Early to Late Adolescence: Associations with Parental Monitoring and Peer Deviance. Psychol Violence, 9(2): 196-208.

Miranda, D. \& Claes, M. (2004). Rap music genres and deviant behaviors in French Canadian adolescents. Journal of Youth and Adolescence, 33(2), 122-133.

Moffitt, T.E. (2006). Life-course persistent versus adolescence-limited antisocial behavior In D. Cicchetti, \& D.J. Cohen (Eds.), Developmental Psychopathology: Risk, disorder, and 
Kabir Adewale Adegunju, Influence of Parental Monitoring on Adolescents' Deviant Behaviors...

adaptation (vol. 3, pp. 570-598, 2nd ed.). New York, NY: Wiley. https://doi.org/10.1002/9780470939406.ch15.

Odebode, A. A., Alwajud-Adewusi, M. B., \& Akinyemi, O. B. (2017). Causes of examination malpractice as perceived by teachers of secondary schools in Lagos State, Nigeria: Implications for counselling practice. Journal of Educational Foundations and Development. 5, 76-89.

Odebode, A. A. (2019). Perception of Nigerian parents on the influence of visual media on social behavior of children. Ilorin Journal of Sociology. 11 (2); 165-176.

Odebode, A. A. (2020a). Views of Nigerian teachers on strategies for curbing indiscipline: implications for counselling practices. Mimbar Sekolah Dasar, 7 (1); 30-42. https://doi.org/10.17.509/mimbar-sd.v711.23477.

Odebode, A. A. (2020b): Self-image of in-school adolescents in Offa Local Government Area of Kwara State: Implications for Counselling Practices. International Journal of Instruction, 13(1), 523-534.

Odukoya, O. O., Sobande, O. O., Adeniran, A., Adesokan, A. (2018). Parental monitoring and substance use among youths: A survey of high school adolescents in Lagos State, Nigeria. Nigeria Journal of Clinical Practice, 21 (11), 1468-1475.

Oluyemi, J. A., Yinusa, M. A., Abdullateef, R., Kadir, K., \& Joseph, A. (2017). Parental influence on adolescent sexual behavior among secondary school students in Ogbomoso, Nigeria. African Journal of Social Work, 7(1), 32-40.

Stattin, H., \& Kerr, M. (2000). Parental monitoring: A reinterpretation. Child Development, 71 (4), 1072-1085. https://doi.org/10.1111/1467-8624.00210.

Snyder, J. (2002). Reinforcement and coercion mechanisms in the development of antisocial behavior: Peer relationships In J.B. Reid, G.R. Patterson, \& J. Snyder (Eds.), Antisocial behavior in children and adolescents: A developmental analysis and model for intervention (pp. 101-122).Washington, DC: American Psychological Association. https://doi.org/10.1037/10468-005

Trudeau, L., Mason, W.A., Randall, G.K., Spoth, R., \& Ralston, R. (2012). Effects of parenting and deviant peers on early to mid-adolescent conduct problems. Journal of Abnormal Child Psychology, 40(8), 1249-1264. https://doi.org/10.1007/s10802-012-9648-1. 
Trucco, E.M., Colder, C.R., \& Wieczorek, W.F. (2011). Vulnerability to peer influence: A moderated mediation study of early adolescent alcohol use initiation. Addictive Behaviors, 36(7), 729-736. https://doi.org/10.1016/j.addbeh.2011.02.008.

Yahaya, L. A., Odebode, A. A. \& Akinyemi, O. B. (2017). Types of examination malpractice as perceived by teachers of secondary schools in Lagos State, Nigeria: Implication for counselling practice. Ife PsychologIA. 25 (1), 133-147.

Yahaya, L.A. (2015). Professionalization of counselling in Nigeria. In A.l. Idowu (2nd ed.). Guidance and counselling in Education. Ilorin: University of Ilorin Press. 